\title{
Permanent pacemaker practice at a Scottish district general hospital between 1987 and 1993
}

\author{
John G Doherty, Fiona Dawson, Finlay Kerr
}

\begin{abstract}
Background-Raigmore is a district general hospital offering a permanent pacemaker service to its catchment population of 233500 . It has been argued that the British public would be better served by a less centralised pacing service. There also exists the view, however, that a lower rate of complications and best follow up practice are achieved by specialised centres. The pacemaker practice over a 79 month period (January 1987 to July 1993) was thus reviewed with these issues in mind.
\end{abstract}

Methods-The pacemaker records of all new implantations for the period under observation were reviewed retrospectively. Data were acquired under the headings age, sex, symptoms, electrocardiographic (ECG) indications, and complications (early and late). Comparison was made with United Kingdom national data, a previous audit from Raigmore, and two recently published large series from specialist centres (one British and the other French).

Results-The mean age of patients who underwent implantation was 74 years and $47 \cdot 5 \%$ were male. The most common presenting symptoms were syncope $(46 \%)$, dizzy spells $(24 \cdot 5 \%)$, and heart failure $(11 \cdot 5 \%)$. The most common ECG indications for pacing were complete heart block (wide QRS) (28\%), atrial flutter/fibrillation with bradycardia (21.6\%) and complete heart block (narrow QRS) (9.6\%). The implantation rate was 184/million population/year in 1993. The early and late complication rates were low $(2 \cdot 48 \%)$.

Conclusions-The presence of a pacing centre in a remote part of the United Kingdom fulfils a necessary service and has low complication rates, with implantation rates and patterns that are comparable with those in other parts of the country.

(Br Heart f 1995;73:475-479) Dr F Kerr, Department of Cardiology and General Raigmore Hospital, Perth Road, Inverness IV2 3UJ.
Correspondence to: Medicine, Floor 7 , Accepted for publication 22 November 1994

Cardiology and

General Medicine, Raigmore Hospital, Inverness J G Doherty J G Doherty
Keywords: pacemaker practice; audit of pacemaker practice; district general hospital.
It has been argued that the British public, especially the elderly, would be better served by a less centralised pacing service. ${ }^{1}$ The low rate of implantation in the United Kingdom as a whole compared with that of Continental Europe or the United States has been attributed to a conservative approach by physicians (especially non-cardiologists) in referring patients for pacing ${ }^{12}$ and it has been shown that the appointment of a cardiologist or physician with an interest in cardiology to a district general hospital can lead to a significant increase in pacemaker implantation for the locality. ${ }^{3}$ There is a contrary view, that a lower rate of complications and best follow up practices are achieved by large specialised centres. ${ }^{4}$ A previous report from this centre reviewed our practice from December 1978 to December 1986 and commented on complication rates and the effect of establishing a pacing service at a district general hospital. ${ }^{3}$ These issues and the practice of dual chamber pacing introduced in 1990 are reviewed in the present audit performed between January 1987 and July 1993. Our data are compared with United Kingdom national values $^{5}$ and with two recently published large series from specialist centres. ${ }^{46}$

\section{Background}

The facilities at Raigmore District General Hospital remain largely unchanged since the first pacemaker was implanted in December 1978. All procedures are carried out by an experienced operator (FK), a consultant physician with an interest in cardiology, apart from a small number of implantations performed by two middle grade staff on short rotation from large cardiological centres. The service was confined to single chamber implantation until the introduction of dual chamber pacing in 1990 . As for our previous audit, implantations continue to be carried out under local anaesthesia in a surgical theatre using fluoroscopic screening. Antibiotic prophylaxis is given routinely using a combination preparation of ampicillin/ flucloxacillin or cefuroxime for patients with penicillin allergy. The subclavian vein is the preferred route of access. Assisting staff comprise two theatre nurses, one technician responsible for physiological measurements, 


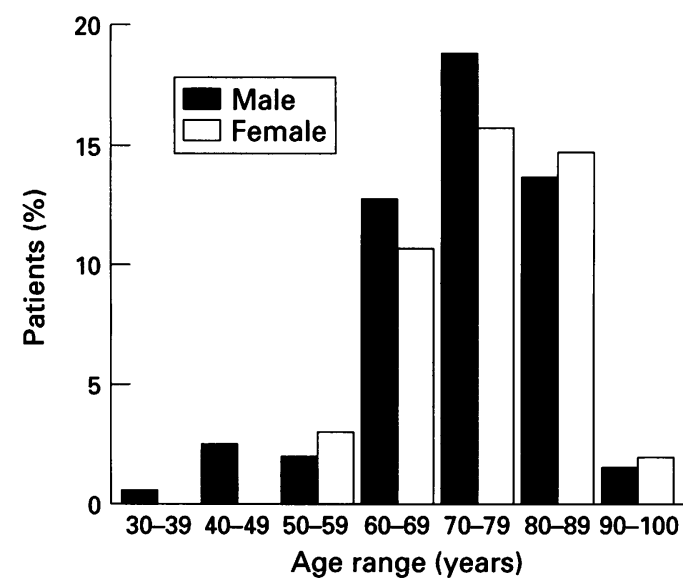

Age and sex distribution of patients having new implants between 1987 and 1993.

\section{Method}

The pacemaker records of all new implantations for the period under observation were reviewed. Of a total of 254 procedures performed over the 79 month period, 201 were new implants, 42 pulse generator replacements, 10 total system reimplantations, and one electrode replacement. Data were acquired retrospectively under the headings age, sex, symptoms, electrocardiographic (ECG) indications, and complications for patients with new implanted systems. The modes of pacing used were also reviewed.

Replacement procedures (pulse generator and total system) were performed on a routine basis on a different cohort of patients to that audited here and includes those moving to this area who had implants performed elsewhere.

\section{Results}

The figure shows the age and sex distribution of patients with new implants, with a peak for men and women in the 70-79 age group. The mean age was 74 years and $47.5 \%$ were male. The values are similar to United Kingdom national data 1992 (mean age 71.9 years;

Table 1 Presenting symptoms leading to pacemaker implantation

\begin{tabular}{llll}
\hline & $\begin{array}{l}\text { Raigmore District } \\
\text { General Hospital } \\
(\%)\end{array}$ & $\begin{array}{l}\text { Papworth Hospital } \\
(\%)^{6}\end{array}$ & $\begin{array}{l}\text { United Kingdom } \\
\text { national data 1992 } \\
(\%)^{5}\end{array}$ \\
\hline Syncope & 46 & 58 & $37 \cdot 5$ \\
Dizzy spells & 24.5 & 23 & 24 \\
Bradycardia & 1.9 & $9 \cdot 3$ & $6 \cdot 5$ \\
Heart failure & $11 \cdot 5$ & 9 & $4 \cdot 3$ \\
Unspecified & $5 \cdot 2$ & 0 & 21 \\
\hline
\end{tabular}

Table 2 Electrocardiographic indications for pacemaker implantation

\begin{tabular}{llll}
\hline & $\begin{array}{l}\text { Raigmore District } \\
\text { General Hospital } \\
(\%)\end{array}$ & $\begin{array}{l}\text { Papworth Hospital } \\
(\%)^{6}\end{array}$ & $\begin{array}{l}\text { United Kingdom } \\
\text { national data 1992 } \\
(\%)^{5}\end{array}$ \\
\hline AV block & $56 \cdot 4$ & $55 \cdot 6$ & $40 \cdot 93$ \\
Sick sinus syndrome & $12 \cdot 7$ & 20.9 & $17 \cdot 72$ \\
Atrial fibrillation/flutter & $21 \cdot 6$ & $13 \cdot 2$ & $12 \cdot 1$ \\
$\quad$ with bradycardia & 5 & $6 \cdot 1$ & $2 \cdot 62$ \\
Bundle branch block & $4 \cdot 3$ & $<5$ & $22 \cdot 22$ \\
\hline Other & & & \\
\hline
\end{tabular}

$\mathrm{AV}$, atrioventricular. male $56 \%) .{ }^{5}$ In the previous Raigmore audit the mean age was also 74 years and $46 \%$ were male. $^{3}$

The most common presenting symptoms were syncope $(46 \%)$, dizzy spells $(24 \cdot 5 \%)$, and heart failure $(11 \cdot 5 \%)$. Table 1 gives United Kingdom national data $(1992)^{5}$ and recently published audit data from Papworth Hospital $^{6}$ juxtaposed to the Raigmore data.

Table 2 outlines the ECG indications at the time of implantation. Complete heart block (wide QRS) was the most common indication (28\%), followed by atrial flutter/fibrillation with bradycardia $(21 \cdot 6 \%)$ and complete heart block (narrow QRS) $(9 \cdot 6 \%)$. The total percentage for all forms of atrioventricular block was $56 \cdot 4 \%(2 \cdot 4 \%$ first degree block, $15.4 \%$ second degree block, $38.6 \%$ complete heart block). Current national data for ECG indications are again juxtaposed with those from our audit. Additionally, the Papworth data, ${ }^{6}$ also juxtaposed, show similar patterns of ECG indications for pacemaker implantation to those of our own.

Of patients who underwent pacing at Raigmore hospital, only $12 \cdot 7 \%$ had sick sinus syndrome which is lower than the UK national average $(17 \cdot 72 \%)^{5}$ or the Papworth value $(20.9 \%){ }^{6}$

A total of 164 single chamber units were implanted during the period under review of which 151 were VVI, 11 atrial pacemakers, and two VVIR.

Dual chamber pacing was started at Raigmore hospital in 1990 and up to the time of audit, 37 new systems had been implanted (all DDD); 54\% were implanted for complete heart block, $27 \%$ for second degree heart block, and $8 \cdot 1 \%$ for sick sinus syndrome. Two patients with VVI systems were upgraded to DDD in view of pacemaker syndrome.

Early complications were defined as those occurring in the 6 weeks after implantation and late complications as those occurring thereafter. Infection requiring removal of the system occurred in only one case; no organisms grew on culture. There were three cases of pocket haematoma formation which required evacuation. One cardiac arrest (asystole) requiring external cardiac massage occurred during implantation and responded to isoprenaline; the patient was an elderly woman with complete heart block whose pacemaker was implanted under general anaesthesia due to poor patient cooperation. The overall early complication rate was $2.48 \%$ and is compared in table 3 with data from two large centres with recently published series.

The only complicated dual chamber system presented with unexplained superficial wound erosion at 4 months. Because this continued to recur, consideration was given to patient induced artefact but this was never proven. Superficial erosion continues intermittently and is managed by wound dressing. This system was complicated by atrial lead adaptor disconnection at 14 months but 
Table 3 Complications of pacemaker implantations

\begin{tabular}{ll}
\hline & $\begin{array}{l}\text { Complication } \\
\text { rate }(\%)\end{array}$ \\
\hline Early complications & \\
Raigmore District General Hospital & $2 \cdot 48$ \\
Papworth Hospital $^{6}$ & 2 \\
St Cloud group & \\
Late complications & $2 \cdot 8$ \\
Raigmore District General Hospital $^{6}$ & $2 \cdot 48$ \\
\hline
\end{tabular}

Table 4 Numbers and rates of new implantations

\begin{tabular}{|c|c|c|}
\hline \multirow[b]{2}{*}{ Year } & \multirow{2}{*}{$\begin{array}{l}\text { No of new implantations } \\
\text { at Raigmore hospital }\end{array}$} & Implantation rate (no/million population/year) \\
\hline & & Raigmore hospital ${ }^{\star}$ United Kingdom national data \\
\hline $\begin{array}{l}1987 \\
1988 \\
1989 \\
1990 \\
1991 \\
1992 \\
1993\end{array}$ & $\begin{array}{l}17 \\
23 \\
38 \\
27 \\
28 \\
45 \\
43+\end{array}$ & 184 \\
\hline
\end{tabular}

*Values for 1978 and 1986 were 22 and 152 respectively. fUpdated to 12 months.

because of wound problems this has not been repaired.

All other late complications occurred in VVI systems. Loss of telemetry occurred in a single case because of radiotherapy for breast carcinoma 3 years after insertion and rendered interrogation of the generator impossible. The pulse generator was replaced. An 84 year old man with complete heart block presented 5 months after implantation with pulse generator erosion and evidence of Staphylococcus aureus infection. It was possible to replace the pulse generator and retain the electrode. The third late complication in a VVI system occurred in a 65 year old woman with Mobitz 2 block. In 1988 an epicardial system was inserted in view of difficulty in obtaining a stable lead position in the ventricle. This was complicated by a high threshold and impaired sensing; the pulse generator could not be reprogrammed and thus a transvenous pacemaker with a screw in electrode was inserted in 1992. The transvenous system remains complicated by a high pacing threshold at $4 \mathrm{~V}$. The overall late complication rate was $2 \cdot 48 \%$.

Table 4 reviews in profile the implantation level since 1987 . There has been a sustained increase in pacing levels with an implantation rate for 1993 at 184/million/population/year.

\section{Discussion}

Since our last review, the rate of pacemaker implantation has almost doubled (201 new implants in 79 months $v 129$ implants in 96 months). Our average implantation rate over the 67 months (130/million population/year) compares with the United Kingdom national 1989 value of $148 /$ million population/year. ${ }^{5}$ An update on United Kingdom pacing data showed the implant rate for 1992 to be $202 /$ million population/year $^{7}$; our implant rate for $1992-1993$ was $184 /$ million population/ year. Clearly, the stimulus provided by creating a pacemaker service at this district general hospital has led to a sustained increase in pacing levels.
Insertion of dual chamber systems was started at Raigmore in 1990 and the dual chamber implantation rate over the period 1991-1992 was $28 \%$ of total implants which is close to the United Kingdom national average $(24 \%),{ }^{5}$ although lower than North American rates (32\%). ${ }^{8}$ The trend towards an increased rate of insertion of dual chamber systems is in accordance with pacing guidelines from the British Pacing and Electrophysiology Group 1991.9

Maintenance of atrioventricular synchrony in patients with atrioventricular block has been shown to improve effort tolerance and subjective variables such as dyspnoea, palpitation, and general wellbeing. ${ }^{10}$

We agree with findings from the Freeman hospital, however, that in patients with limited mobility, especially the elderly, other factors must be taken into account and the potential benefits of physiological pacing weighed against the disadvantages. ${ }^{11}$ Accordingly, most elderly patients with bradyarrhythmia other than sick sinus syndrome were given a VVI system. Those patients given a dual chamber system were selectively chosen according to expectations of exercise capacity and general physical condition.

It is our policy for patients with sick sinus syndrome to use an atrial pacemaker in the absence of any evidence of atrioventricular block. There is consensus on the advantages of atrial pacing in sinus node dysfunction with a reduction in the incidence of atrial fibrillation, systemic embolism, and heart failure and possible prolongation of life. ${ }^{12}{ }^{13}$ The incidence of atrioventricular block in sinus node disease has been estimated at only $0.6 \%$ each year with about $2 \%$ of patients requiring upgrade of their atrial pacemaker to a dual chamber system. ${ }^{14} \mathrm{We}$ do acknowledge that some investigators have reported a higher incidence of atrioventricular conduction disturbance ${ }^{15}$ but, to date, none of our patients with an atrial lead for sinus node disease has required an upgrade to dual chamber pacing.

The proportion of patients receiving a pacemaker for sinus node disease is low compared with United Kingdom national rates. ${ }^{5}$ This may be explained by our policy to restrict pacing in sinoatrial disorder to patients who are symptomatic. There is no evidence that pacing asymptomatic patients with sinus node disease improves prognosis. ${ }^{16}$

Our complication rates for single and dual chamber implantations are low and compare favourably with two large recently published reviews of single chamber pacing at specialist units. ${ }^{46}$ Guidelines from the 1970 s suggested that a complication rate $>5 \%$ should raise questions regarding the overall quality of an implantation programme. ${ }^{17}$ The Papworth group experienced a $2 \%$ early complication rate in implanting 1136 single chamber ventricular permanent pacemakers. ${ }^{6}$ The St Cloud group experienced an early complication rate of $2 \cdot 8 \%$ for 1951 single chamber ventricular permanent pacemakers implanted between 1987 and 1992. ${ }^{4}$ The French group 
suggest that pacemaker implantation and follow up should be performed in only specialised centres but the Papworth group clearly showed that an experienced operator can achieve complication rates $<3 \%$ even when undertaking $<12$ implants each year. An experienced operator at Raigmore hospital has achieved a low early complication rate $(2 \cdot 48 \%)$ while implanting an average of 31 new systems a year.

Our late complication rate of $2 \cdot 48 \%$ is low, although there are few data in the literature with which to compare. Equally, there is little in the literature with which to compare complication rates in dual chamber implantation. The transition to more complex forms of pacing at this centre, however, was achieved without any increase in complication rates.

We believe that our low complication rates vindicate the role of the district general hospital as a pacing centre. Additionally, the presence of a pacing centre in a remote part of the United Kingdom continues to stimulate an increasing demand for cardiac pacing with implantation rates that are comparable with those in other parts of the country.

We thank Ms Helen Brough, clinical audit assistant, Hilton Hospital, Inverness who computerised the data and Dr Richard G Charles, consultant cardiologist, Broadgreen Hospital, Liverpool with whom Dr F Kerr gained initial experience of dual chamber implantation. The source for the Highlands and Islands population figures was Scottish Health Statistics (1993).

1 Rickards AF. Where's the block? BMF 1984;288:737-8. 2 Nathan AW, Paul VE, Judge K, Camm AJ. Survey of the attitudes of British physicians to pacing. Br Heart $\mathcal{f}$ 1994;71:96-101.
3 Godden DJ, MacCulloch M, Sandhu P, Kerr F. Correcting a block? Successful experience of a small British pacing centre. Br Heart f 1987;58:495-8.

4 Mugica J, Ritter P, Lazarus B, et al. Evolution of early complications after ventricular single chamber pacemaker implants in a specialist centre: 9483 patients over 24 years. Eur $f$ Cardiac Pacing Electrophysiol 1993;3: 24 years $21-6$.

5 UK National Pacing Database Annual Report. June 1992. British Pacing and Electrophysiology Group (BPEG), London

6 Hall JA, Grace AA, Newell SA, et al. Prospective evaluation of the early complications of 1136 single chamber permanent pacemaker implantations. Eur $f$ Cardiac Pacing Electrophysiol 1993;3:14-20.

7 UK National Pacing Database. Updated Report February 1994. British Pacing and Electrophysiology Group (BPEG), London.

8 Parsonnet V, Bernstein AD. The 1989 World Survey of Cardiac Pacing. PACE 1991;14:2073-6.

9 Clarke M, Sutton R, Ward D, et al. Recommendations for pacemaker prescription for

10 Perrins JE Morley CA, Chan SL Sutton R Randomised controlled trial of physiological and ventricular pacing. controlled trial of physiolo

11 Ray SG, Griffith MJ, Jamieson S, et al. Impact of the recommendations of the British Pacing and Electrophysiology Group on pacemaker prescription and on the immediate costs of pacing in the Northern region. Br Heart $₹$ 1992;68:531-4.

12 Rosenqvist M, Brandt J, Schuller H. Long term pacing in sinus node disease; effects of stimulation mode on cardiovascular morbidity and mortality. Am Heart $\mathcal{f} 1988$ 116:16-22.

13 Bianconi L, Boccadamo R, Di Florio A, et al. Atrial versus ventricular stimulation in sick sinus syndrome: effects on morbidity and mortality [abstract]. PACE 1989;12: 1236.

14 Rosenqvist $M$, Obel IW. Atrial pacing and the risk for AV block: is there a time for a change in attitude? $P A C E$ 1989;12:97-101.

15 Sasaki Y, Shimotori M, Akahane K, et al. Long-term follow-up of patients with sick sinus syndrome: a comparison of clinical aspects among unpaced, ventricular parison of clinical aspects among unpaced, ventricular
inhibited paced and physiologically paced groups. inhibited paced and phys

16 Shaw DB, Holmann RR, Gowers JI. Survival in sinoatrial disease (sick-sinus syndrome). BMF 1980;280:139.

17 Parsonnet V, Furman S, Smyth NPD. Implantable cardiac pacemakers: status report and resource guidelines. Inter-Society Commission on Heart Disease Resources (IHCD). Circulation 1974;50A:21-35. 
before any clinical component of their course; recent recommendations that all applicants to medical school should be screened, and immunised if appropriate, have far-reaching implications and have provoked controversy. ${ }^{17} 18$

In conclusion, among invasive cardiologists in the United Kingdom there is clear scope for improvement in vaccine uptake, particularly in completion of the immunisation regimen. Screening of patients, as recommended, should also be performed. Careful practice to avoid needle stick injury should continue and immunisation should also be offered to nursing and other ancillary staff caring for patients undergoing invasive cardiac procedures.

We thank Dr J Heptonstall, Consultant Medical Microbiologist, Public Health Laboratory Service Communicable Disease Surveillance Centre, London for invaluable advice before the preparation of this report. We also thank all those who completed and returned the questionnaire.

1 Recommendations of the Advisory Group on Hepatitis Protecting health care workers and patients from hepatitis Protecting health care work

2 Zuckermann A. Who should be immunised against hepatitis B? BMF 1984;289:1243

3 Recommendations of the Expert Advisory Group on AIDS Guidance for clinical health care workers: protection against infection with HIV/hepatitis B. HMSO, London 1990.

\section{CORRECTIONS}

Failure of "effective" treatment for heart failure to improve normal customary activity. $\mathcal{F} T \mathrm{Walsh}, R$ Andrews, $A$ Evans, $A \mathcal{F}$ Cowley (Br Heart $\mathcal{f}$ 1995;74: 373-6).

Exercise ventilation after balloon dilatation of the mitral valve. A P Banning, N P Lewis, $\mathcal{f} S$ Elborn, $R \mathcal{F}$ $C$ Hall (Br Heart $\mathcal{F} 1995 ; 74: 386-9)$.

We regret that the incorrect volume number was given in the strap lines and at the foot of the abstracts of these papers. The correct volume number is 74

Permanent pacemaker practice at a Scottish district general hospital between 1987 and 1994. $\mathcal{F} G$ Doherty, F Dawson, F Kerr

We regret that an error appeared in the second sentence of the discussion on page 477 of this article $(\mathrm{Br}$ Heart $\mathcal{F}$ 1995;73:475-8) which should have read, "Our average implantation rate over the 79 months $(130 / \mathrm{mil}$ lion population/year) compares with the United Kingdom national 1989 value of 148 /million population/year." $"$
4 Centers for Disease Control guidelines for prevention of HIV and hepatitis B viruses to health care and public safety workers. $M M W R$ 1989;38(suppl 56, 4-5):31-3.

5 Department of Health. Immunisation against infectious diseases. London: HMSO, 1992:110-9.

6 Polakoff S. Acute viral hepatitis B, reported to the Public Health Laboratory Service. F Infect 1990;20:163-8.

7 Heptonstall J. Outbreaks of hepatitis B virus infection associated with infected surgical staff. Communicable Disease Report 1991;1(8):R81-5.

8 Cartwright A. Professionals as poor responders: variations in and effects of response rates to questionnaires 1961-77. BMF 1978;ii:1419-21.

9 Editorial. Few physicians vaccinated against hepatitis B. Wis Med $\mathcal{F} 1989 ; 88: 14$.

10 Kinnersley P. Attitudes of general practitioners towards their vaccination against hepatitis B. BMf 1990;300:238.

11 Burden AD, Whorwell PJ. Poor uptake of hepatitis B immunisation amongst hospital-based health care staff. Postgrad Med F 1991;67:256-8.

12 Buss PW, McCabe M, Verrier Jones ER. Attitudes of paediatricians to HIV and hepatitis B virus infection. Arch Dis Child 1991;66:961-5.

13 Berridge DC, Galea MH, Evans DF, Pugh S, Hopkinson BR, Makin GS. Hepatitis B immunisation in vascula surgeons. Br f Surg 1990;77:585-6.

14 Williams JR, Flowerdew ADS. Uptake of immunisation against hepatitis $B$ among surgeons in Wessex Regional Health Authority. BMF 1990;301:154.

15 Le F, Porteous MJ. Operating practices of and precautions taken by orthopaedic surgeons to avoid infection with HIV and hepatitis B virus during surgery. BMF 1990; 301:167-9.

16 Lever AML. Treatment of the chronic hepatitis B virus carrier state. $\mathcal{F}$ Infect 1988;16:221-9.

17 Lever AML. Editorial: Hepatitis B and medical studen admission. $B M F$ 1994;308:870-1.

8 Kingman S. Hepatitis B status must be known for medical school. $B M \Im$ 1994;308:876.

The 1996 Annual General Meeting of the British Cardiac Society will take place at the Scottish Exhibition \& Conference Centre, Glasgow from 7 to 9 May.

The Fourth Annual Molecular Symposium at UCL Medical School on Ischaemic Preconditioning and Adaptation to Ischaemia will take place on 12 December 1995 in London. For further information please contact Jan Wenley, Symposium Administrator, Department of Molecular Pathology, 46 Cleveland Street, London W1P 6DB (tel: +44 171380 9343; fax: +44 1713873310 ). 